\title{
O potencial da paisagem urbana como atratividade turística: um estudo sobre a paisagem de Brasília-DF
}

the potential of the urban landscape as tourist attractiveness: a study on the landscape of Brasília - DF

Le potentiel du paysage urbain en tant que attraction touristique : une étude sur le paysage de Brasília - DF

El potencial del paisaje urbano como atracción turística: un estudio en el paisaje de Brasília - DF

\author{
Josildete Pereira de Oliveira* \\ Francisco Antonio dos Anjos** \\ Fabiana Calçada de Lamare Leite ${ }^{* * *}$
}

Recebido em 4/8/2007; revisado e aprovado em 10/3/2008; aceito em 22/7/2008.

\begin{abstract}
Resumo: Este artigo é resultado de um estudo exploratório sobre o potencial da paisagem urbana de Brasília para o turismo. Especificamente, a área correspondente ao Eixo Monumental do Plano Piloto. Esta reflexão procurou dar ênfase ao conceito da percepção e interpretação do significado da imagem da cidade, a partir do qual o estudo da forma que configura a paisagem urbana se faz importante tanto quanto o processo cultural de apropriação dessa paisagem pelo usuário. A análise procurou inferir sobre os aspectos que podem suscitar uma discussão sobre a perspectiva do observador/visitante em sua experiência turística.

Palavras-chave: Arquitetura. Paisagem Urbana. Turismo.

Abstract: This article is resulted of a Exploratory study on the potential of the urban landscape of Brasilia for the tourism. Specifically, the corresponding area to the Eixo Monumental of the Plano Piloto. This reflection looked for to give to emphasis to the concept of the perception and interpretation of the meaning of the image of the city, from which the study of the form that configures the urban landscape if it in such a way makes important how much the cultural process of appropriation of this landscape for the user. The analysis looked for to infer on the aspects that can excite a quarrel on the perspective of the visiting observer/in its tourist experience.

Key words: Architecture. Urban Landscape. Tourism.

Résumé: Cet article a été originé d'une étude sur le potentiel turistique du paysage urbain de Brasília. Plus particulierment, la région urbaine dénomée l’Axe Monumental du Plan Pilote de la Capitale du Brésil. Cette réflexion a mis au point le concept sur la pérception et l'interpretation du significat de l'image urbaine, qui met en valeur l'étude de la forme, ainsi que le processus culturel d'assimilation du paysage par les utilisateurs. L'analyse a signalé les aspects qui peuvent susciter la discussion sur la perspective touristique de ce paysage.

Mots-clé: Architecture. Paysage Urbain. Tourisme.

Resumen: Este artículo es el resultado de un estudio exploratorio sobre el potencial del paisaje urbano de Brasilia para el turismo. En concreto, la superficie correspondiente al Eixo Monumental del Plano Piloto. Esta reflexión ha puesto de relieve el concepto de percepción e interpretación del significado de la imagen de la ciudad, a partir de la cual el estudio de la forma en que configura el paisaje urbano es importante, ya que el proceso de la propiedad de paisaje cultural por el usuário. El análisis tratado de inferir en las cuestiones que puedan plantear un debate sobre la perspectiva del observador / usuario en su experiencia turística

Palabras clave: Arquitectura. Paisaje Urbano. Turismo.
\end{abstract}

\section{Introdução}

A implantação de Brasília no final da década de 50, durante o governo de Juscelino Kubitschek, é favorecida pelo contexto de expansão e redistribuição urbana para o cen- tro do país, seguido da complementação do sistema de transportes e da melhoria das comunicações como uma condição material para unificar o território. A criação de uma unidade territorial integrada, também foi favorecida pela existência de um Projeto

\footnotetext{
* Arquiteta e Urbanista pela UFBA. Mestre em Natureza, Meio Ambiente, Sociedade e Doutora em Geografia pela Université de Caen-Basse Normandie - França. Docente do Programa de Pós-Graduação Stricto Sensu - Mestrado Acadêmico em Turismo e Hotelaria e do Curso de Arquitetura e Urbanismo da Universidade do Vale do Itajaí - SC - Brasil. E-mail: joliveira@univali.br

** Graduado em Geografia (UNIVALI). Mestre em Geografia e Doutor em Gestão Ambiental (UFSC). Pós-doutorado em Geografia (UNESP-PP) Professor e Pesquisador do Curso de Mestrado em Turismo e Doutorado em Administração e Turismo (UNIVALI). E-mail: fsanjos@terra.com.br

*** Graduada em Geografia pela Universidade Federal Fluminense (UFF/RJ), MBA em Turismo pela UNIVERCIDADE (RJ), mestranda em Turismo e Hotelaria pela Universidade do Vale do Itajaí (UNIVALI). Bolsista CNPq - AT/NS. E-mail: fabianadelamare@yahoo.com.br
} 
Nacional em que continha uma política de desenvolvimento onde constava a construção da cidade de Brasília, com suas interligações com o resto do território.

Segundo Yázigi (2003), a construção de uma nova cidade gera a "construção" de uma nova paisagem. A paisagem está associada à passagem do tempo sobre um determinado local, às percepções das formas e do mundo. Essa percepção passa pela visão que nos conduz a múltiplos processamentos de informações percebidas no meio, onde o arranjo espacial das formas que configura uma paisagem é tão importante quanto o processo cultural que lhe é apropriado. Assim, a arquitetura deve ser considerada como parte de um todo. A profusão de formas arquitetônicas que constituem uma cidade é reveladora de sua história, cultura, forma e muitas outras informações que interessam tanto ao estudioso quanto ao possível visitante.

Este artigo é resultado de um estudo exploratório realizado sobre a paisagem urbana de Brasília e sua potencialidade como atrativo turístico, focado principalmente na área urbana correspondente ao Eixo Monumental do Plano Piloto, com sua expressão monumental e com características geográficas que a individualizam no cenário nacional.

Considerando que cada cidade possui uma paisagem específica, em função do desenho urbano e das características do sítio geográfico de implantação, esta reflexão procurou ressaltar que a análise da paisagem edificada, embora seja provida de uma base conceitual consistente, é também resultante da percepção do observador. Neste sentido, o estudo da forma ou do arranjo urbanístico que configura a paisagem de uma cidade se faz importante tanto quanto o processo cultural de apropriação dessa paisagem por quem a observa.

O conceito que norteou a análise foi o da percepção e interpretação do significado da imagem da cidade, cuja análise procurou inferir sobre os aspectos mais significativos que podem suscitar uma discussão sobre a apreensão e significado dessa paisagem a partir da perspectiva do observador/visitante, eventualmente durante a sua experiência turística.

Assim, no primeiro momento da discussão procurou-se discorrer sobre os con- ceitos de paisagem e sobre o aporte teórico de vários autores focados na percepção ambiental, na imagem urbana e na semiologia do espaço como um referencial da análise. Em seguida, a discussão se atém à análise da paisagem do Eixo Monumental de Brasília e seu potencial como atratividade turística.

\section{Brasília: criação, localização e forma}

Brasília começa a existir na primeira constituinte do império Brasileiro, em 1823, numa proposta colocada pelo inconfidente mineiro José Bonifácio de Andrade e Silva, argumentando quanto à necessidade da mudança da Capital para um ponto mais central do interior do País e sugerindo ainda para a cidade o próprio nome que recebeu efetivamente.

No dia 7 de setembro de 1922 é lançada a pedra fundamental de Brasília e na década de 1950 essa idéia começa a ser articulada. Por inspiração do Presidente Juscelino Kubitscheck de Oliveira, precisamente em 1956, foi criada a NOVACAP, empresa pública para planejar e executar a construção da nova capital. No dia 21 de abril de 1960, Brasília é oficialmente fundada. O projeto para o Plano Piloto foi escolhido por meio de um concurso promovido pela NOVACAP em 1957, do qual participaram urbanistas de renome internacional. A proposta premiada foi a de Lúcio Costa, definida pela comissão julgadora como "clara, direta e fundamentalmente simples". Em três anos, foi construído o Plano Piloto, cuja proposta urbanística original foi implantada, com alterações insignificantes aprovadas pelo autor.

O Distrito Federal, onde Brasília se localiza com suas cidades de entorno, é dividido em 29 Regiões Administrativas, sendo a Região Administrativa 01, correspondida pela capital federal. Localizada no Distrito Federal, Brasília situa-se entre os paralelos $15^{\circ} 30^{\prime}$ e $16^{\circ} 03^{\prime}$ de latitude sul, os rios Preto, a leste, e Descoberto, a oeste. A longitude no extremo leste é $47^{\circ} 25^{\prime} \mathrm{W}$ e no extremo oeste, $48^{\circ} 12^{\prime}$ W. Em relação aos aspectos físicos, por sua localização geográfica e a combinação de demais fatores influentes, a capital federal é característica da vegetação de cerrado, possui uma temperatura média de $20,5^{\circ} \mathrm{C}$, sendo o mês de setembro o mais quente (má- 
xima de $29^{\circ} \mathrm{C}$ ) e julho, o mês mais frio (mínima de $13^{\circ} \mathrm{C}$ ). O clima é chuvoso e quente de setembro a abril e ensolarado e seco de maio a agosto. Característica que confirma a umidade relativa do ar baixa no inverno, em torno de $25 \%$ e $68 \%$ no verão. A Altitude média da capital é de 1.100 metros.

Segundo o IBGE, Brasília possuía, em 2007, uma área de $5.802 \mathrm{~km}^{2}$ e 2.455 .903 habitantes, resultando em uma densidade demográfica estimada em 407,3 habitantes por quilômetro quadrado.

A economia da cidade é baseada, conforme dados do IBGE (2005), em comércio e serviços, notadamente o serviço público por ser a capital federal, apresentando um PIB de 80,5 bilhões de reais, o que representa $3,75 \%$ de todo o PIB brasileiro (IBGE, 2005). A atividade econômica mais importante da cidade resulta de sua própria proposta inspiradora, ou seja, sua função administrativa. Segundo os dados do IBGE a área urbana correspondente ao plano piloto de Brasília possui atualmente um dos maiores índices de renda per capita do Brasil. No conjunto das atividades de serviço, o turismo merece atenção, por se tratar de um segmento significativo na geração de emprego e renda.

Para a construção de Brasília vieram pessoas de várias regiões do País. Assim, a cidade recebeu distintas formas de apreensão do espaço trazidas por sotaques, culturas e costumes de indivíduos que vinha de todas as regiões do Brasil, mobilizados para a execução da cidade, considerada um empreendimento histórico. Mas, Brasília é uma cidade essencialmente concebida e construída segundo o conceito da arquitetura moderna, no que se refere à sua forma urbanística e consequentemente sua paisagem edificada. Este fato, até então inédito no país, certamente influenciou a assimilação de novos hábitos e práticas sociais de uso e apropriação do espaço urbano.
Evidentemente, o plano urbanístico e sua monumental expressão arquitetônica fizeram de Brasília um marco mundial da arquitetura moderna. Em decorrência, a Capital do Brasil foi o primeiro núcleo urbano construído no século $\mathrm{XX}$ a ser incluído na lista de bens de valor universal, recebendo em 1987 o título de Patrimônio Cultural da Humanidade pela UNESCO.

O plano urbanístico de Lúcio Costa foi concebido em quatro escalas estruturais: a escala monumental, que abarca o Eixo Monumental que, por sua vez, abriga o centro político-administrativa do País; a escala gregária representada por todos os setores de convergência da população; a escala residencial composta pelas Superquadras Sul e Norte e a escala bucólica caracterizada pela arquitetura paisagística de Burle Marx, que permeia as outras três escalas, ou seja as áreas de uso público destinados aos jardins, praças e parques. Da interação dessas quatro escalas nasceu uma cidade que é predominantemente monumental (figuras $01 \mathrm{e}$ 02).

\section{p. 09) afirmou:}

Em sua definição, Lúcio Costa (1991, é também uma cidade cômoda, eficiente, acolhedora eíntima. [...].É ao mesmo tempo uma cidade derramada e concisa, bucólica e urbana, lírica e funcional [...]. Nascida do gesto primário de quem assinala um lugar ou dele toma posse.

Para Lucio Costa, a idéia de uma Brasília monumental não tinha o sentido de ostentação, mas deveria expressar o seu valor como capital. Neste propósito, a idéia foi assimilada prontamente por Oscar Niemeyer em sua arquitetura grandiosa.

Conseqüentemente, a paisagem monumental da cidade é resultado da interação de seus arranjos urbanísticos e arquitetônicos com as características do sítio geográfico de implantação. 


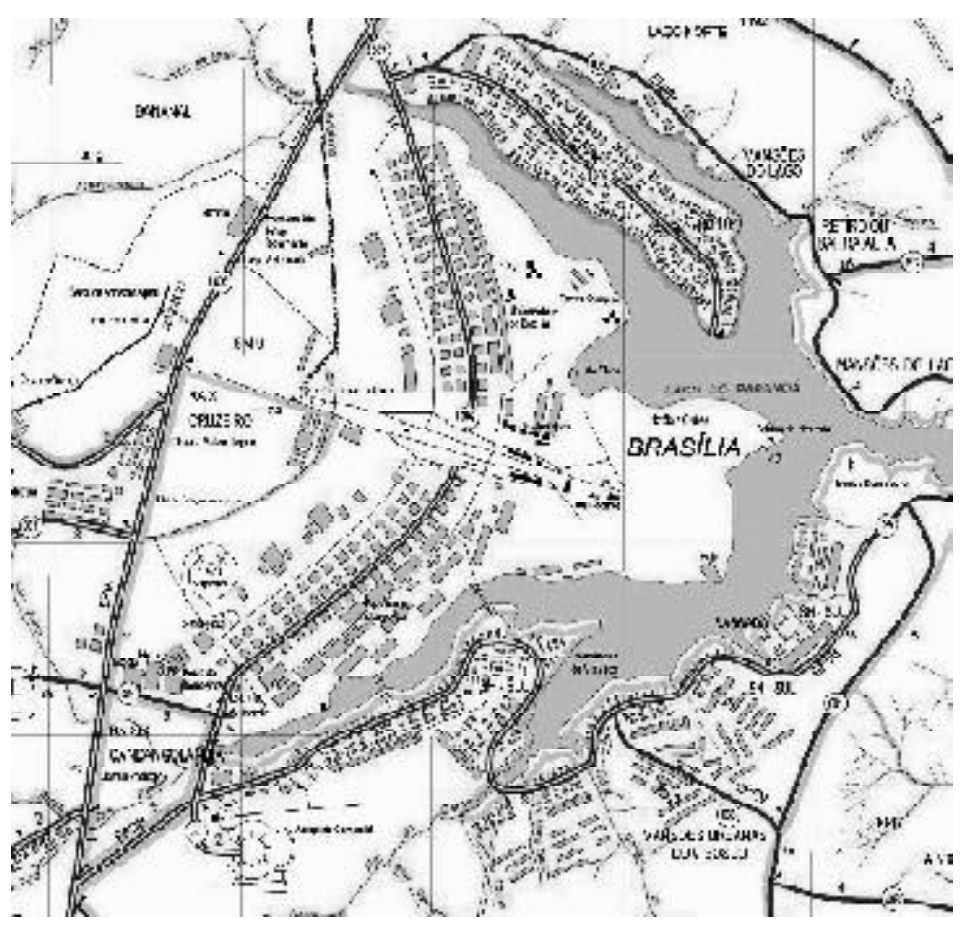

Figura 1 - Brasília

Fonte: http://www. superbrasilia.com

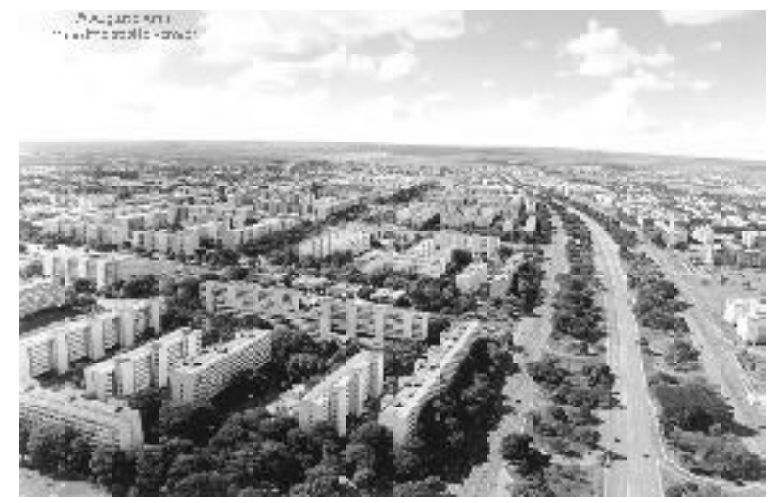

Figura 2 - Vista Panorâmica - Asa Norte. Fonte: http://www.superbrasilia.com

\section{Paisagem: significado, conteúdo e representatividade}

A paisagem é a representação da condição humana e da mudança de tempo no espaço, nela ficam registrados os processos da natureza e ações humanas, cujo ambiente vai se alterando na medida em que esses processos e ações deixam suas marcas.

Segundo De Oliveira (1999), a paisagem é resultado de processos naturais e das ações antrópicas, configurada na escala da percepção humana. Nesse sentido, pode-se dizer que a paisagem é a materialização das ações humanas e/ou de processos naturais ocorridas em uma determinada área no decorrer do tempo.
De acordo com Santos (1982), a paisagem pode ser entendida como o resultado de uma acumulação de tempos. É a forma espacial presente, testemunho de formas passadas que poderão persistir ou não.

Considerando a paisagem urbana como sendo predominantemente um resultado das ações humanas no meio ambiente, seu entendimento e sistematização vêm sendo objeto de vários estudos, na busca de novas abordagens teórico-metodológicas, visando o desenvolvimento de métodos e técnicas para a melhoria da qualidade do ambiente urbano.

As reflexões de Gordon Cullen remetem ao significado da paisagem urbana, sua representatividade e simbolismo com seus efeitos sobre o imaginário social. Assim ele define:

Uma cidade é, antes de mais nada, uma ocorrência emocionante no meio ambiente. Senão, atente-se na pesquisa e nos esforços despendidos para a tornarem uma realidade, empenhado na concretização de uma infinidade de fatores que possibilite a criação de uma organização funcional, viável e saudável. É um tremendo empreendimento humano!". (CULLEN, 1971, p. 10)

Os estudos da paisagem urbana têm enfatizado não apenas os aspectos formais explícitos da configuração, mas atentam também para os valores simbólicos e para os 
processos cognitivos desencadeados em cada indivíduo no seu processo de assimilação da paisagem. Nessa perspectiva, entendemos que o significado e a representatividade da paisagem urbana prepassam os aspectos puramente formais dos elementos que a compõe, na medida em que a sua assimilação resulta também da percepção de cada indivíduo em seu processo cognitivo, mediado por um filtro cultural e por valores simbólicos, como representações do seu imaginário.

Nessa linha de pensamento, os estudos de Kevin Lynch (1987) dão ênfase à imagem da cidade e atentam para a percepção do observador:

As imagens ambientais são o resultado de um processo bilateral entre o observador e o meio ambiente. Este último sugere especificidades e relações, e o observador - com grande capacidade de adaptação e à luz de seus próprios objetivos - seleciona, organiza e confere significado aquilo que vê. A imagem assim desenvolvida limita e enfatiza o que é visto, enquanto a imagem em si é testada, num processo constante de interação, contra a informação perceptiva filtrada. Desse modo, a imagem de uma determinada realidade pode variar significativamente entre observadores diferentes". (Lynch, 1997, p. 7)

Por essa razão, o autor admite que a sua análise limita-se aos aspectos físicos perceptíveis da paisagem urbana, mas chamando a atenção sobre as outras influências atuantes sobre a imaginabilidade: o significado social de uma área, sua função, sua história, ou mesmo seu nome.

A partir dessa premissa, o autor considera que "a forma deve ser analisada para reforçar o significado e não para negá-lo" (Lynch, 1997, p. 51). Assim, em um primeiro momento, pode-se utilizar de alguns elementos formais que caracterizem a paisagem edificada que trazem àquele local legibilidade aos seus usuários. Segundo o autor, um lugar legível é aquele cujos marcos, vias, limites e bairros são facilmente reconhecidos, permitindo uma locomoção mais fácil pela cidade. Além disso, pode servir como um vasto sistema de referências ou um organizador de atividades.

Roberto Boullón (1985) argumenta que a percepção da paisagem urbana não é instantânea, mas é apreendida na medida em que, mesmo em se tratando da imagem parcial, o observador registre, em sucessivas vivências, as informações que o espaço físico transmite por meio de uma série de elementos formais, que este identifica e retém em sua memória. Nessa perspectiva, Kevin Lynch (1997) corrobora, ao defender que a percepção da imagem não é abrangente, mas fragmentada e associada a condições de outra natureza e com quase todos os sentidos em operação.

Considerando a paisagem urbana um atrativo turístico potencial, essa discussão procura evidenciar a condição dessa paisagem no contexto do turismo. Sabe-se que o turismo em ambientes urbanos é de destacada relevância na mobilidade turística mundial, representando quase a totalidade dos espaços preferidos para a visitação. A este fato, assinala-se que a sociedade contemporânea é predominantemente urbana, logo seu horizonte é a cidade e o turismo uma atividade que se organiza a partir da cidade seja como pólo emissor ou receptor. Portanto, a atratividade das paisagens dos pólos receptores é uma variável considerável na análise do potencial turístico das cidades.

Vários autores têm se dedicado ao estudo da paisagem urbana e sua relação com o turismo. Nesse sentido, Castrogiovanni (2001), afirma que é fundamental o estudo dos elementos que compõem a paisagem para saber o motivo pelo qual leva os visitantes a contemplá-las. Pitte apud Castrogiovanni (2002, p. 132), afirma:

a paisagem é uma realidade cultural, pois não é somente trabalho humano, mas também objeto de observações, inclusive consumo. A cultura desempenha um papel de filtro variável de um para outro indivíduo e de um para outro grupo social.

De acordo com Yázigi (2002, p. 7):

As cidades são formadas por uma profusão de formas arquitetônicas, reveladoras de história, tecnologia, virtudes estéticas e muitas outras informações que interessam tanto o estudioso quanto o amador, freqüentemente na posição de turista ou voyeur. (Yázigi, 2002, p. 7).

Para Bullón (2002), as cidades são espaços que o homem cria e constrói, sendo cada cidade diferente da outra, como espaço cultural, pois reflete a expressão da sociedade que ali habita. Esse autor apresenta a arquitetura como uma variável que influencia o visitante a viver uma experiência "antiga" ou "moderna", proporcionando, assim, uma 
viagem no tempo, tanto para o passado como para o futuro.

Portanto, o estudo sobre a paisagem urbana na configuração do espaço turístico de Brasília, nos parece um aspecto chave como potencial de atratividade a ser considerado, até para reforçar outras estratégias de atração turística, como por exemplo, a consolidação do segmento de eventos, que nos parece ser um aspecto já bem explorado pela atividade turística em Brasília.

\section{Brasília: Paisagem e Turismo}

A análise efetuada por este estudo se ateve à área correspondente ao Eixo Monumental Leste, desde a Praça dos Três Poderes (figura 04) até a Estação Rodoviária, passando pela Esplanada dos Ministérios e a Catedral Metropolitana Nossa Senhora Aparecida, e o Eixo Monumental oeste, iniciando pela Estação Rodoferroviária e incluindo a Torre de Televisão (figura 03), Palácio do Buriti, Memorial JK e Praça do Cruzeiro. Esta porção da paisagem da cidade transmite, sobretudo, a harmonia plena entre volumes, espaços e formas valorizada pela linha do horizonte, confirmando a intenção do projeto de Lúcio Costa.

Os extensos gramados verdes sobre o qual surge a arquitetura das edificações, que parece não ter peso sobre o solo, característica da obra de Oscar Niemeyer, conferem leveza e amplidão a esta paisagem.

As fachadas envidraçadas espelham a cidade, multiplicando o reflexo das belas imagens arquitetônicas como um sonho futurista. Essa descrição expressa claramente o aspecto mais amplo do conteúdo, abrangendo uma visão geral da cidade. (COSTA, 1991, p. 17)

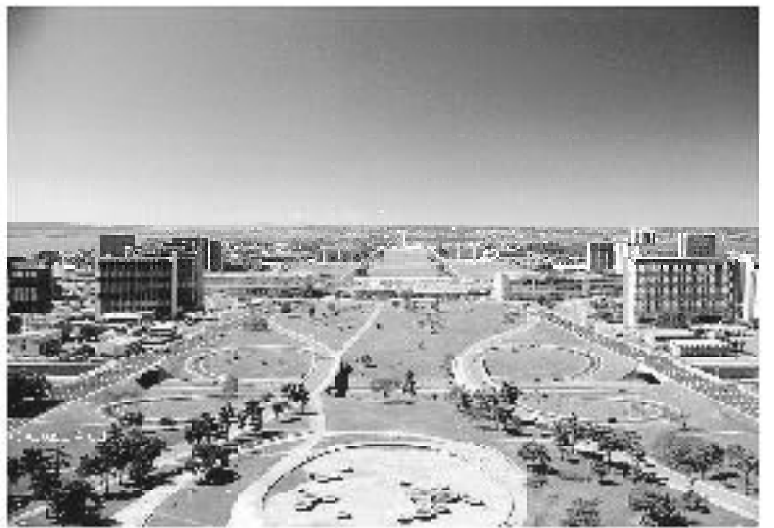

Figura 3 - Vista da Torre de TV - Eixo Monumental

Fonte: http:/ / www.superbrasilia.com

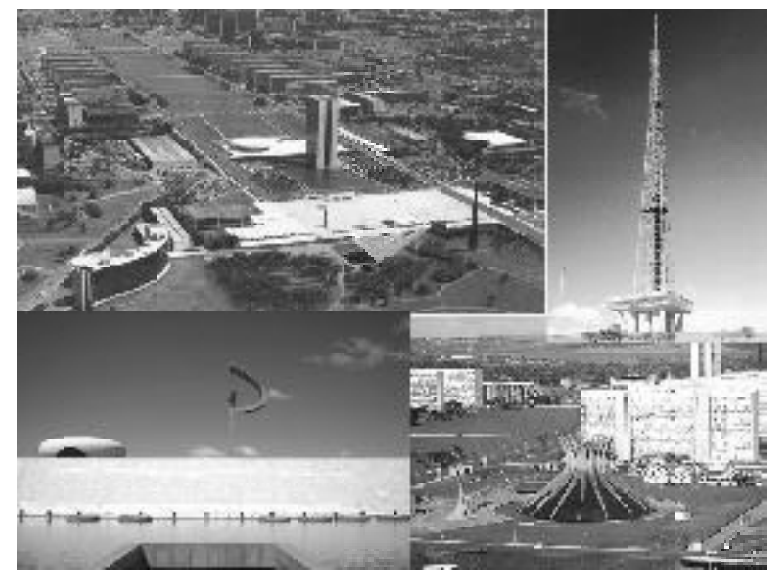

Figura 4 -Praça dos Três Poderes, Torre de TV, Catedral, Memorial JK.

Fonte: http:/ / www.superbrasilia.com

A Praça dos Três Poderes é um amplo espaço cívico que circunscreve o edifício do Congresso Nacional (figura 05), sede do Poder Legislativo, o Palácio do Planalto (figura 06), sede do poder executivo e o Supremo Tribunal Federal, sede do Poder Judiciário. Esse local, como o próprio nome sugere, representa a união dos poderes e, teoricamente, dá significado a historia não só da capital federal, mas do país como um todo.

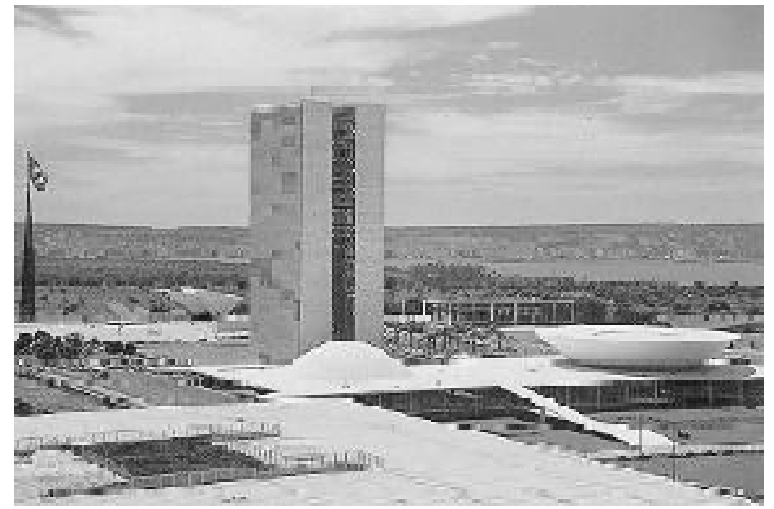

Figura 5 - Congresso Nacional

Fonte: http://www.geocities.com/TheTropics/ 3416/tabfotos.htm

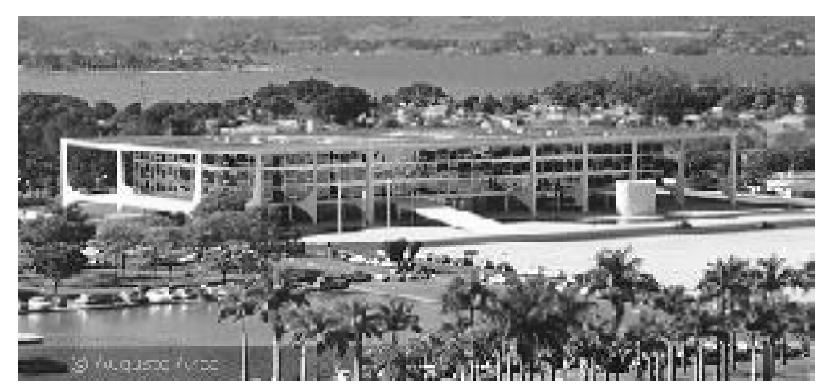

Figura 6 - Palácio do Planalto

Fonte: http://www.geocities.com/TheTropics / 3416/tabfotos.htm 
Assim, a paisagem concreta, ou a paisagem materializada que conforma a Praça dos Três Poderes, extrapola sua dimensão física, emanando significados e representações por todo o país devido aos fatos e medidas que ali se originam. Nessa paisagem ainda é possível apreciar as esculturas Os Guerreiros (figura 8), de Bruno Giorgi, A Justiça (figura 7), de Alfredo Ceschiatti, a Pira da Pátria e o Marco Brasília, de Niemeyer, em homenagem ao ato da UNESCO que considerou a cidade Patrimônio Cultural da Humanidade. Esses monumentos agregam mais representativida de simbólica à Praça dos Três Poderes, já que cada indivíduo se apropria do fato construído codificando seus próprios significados.

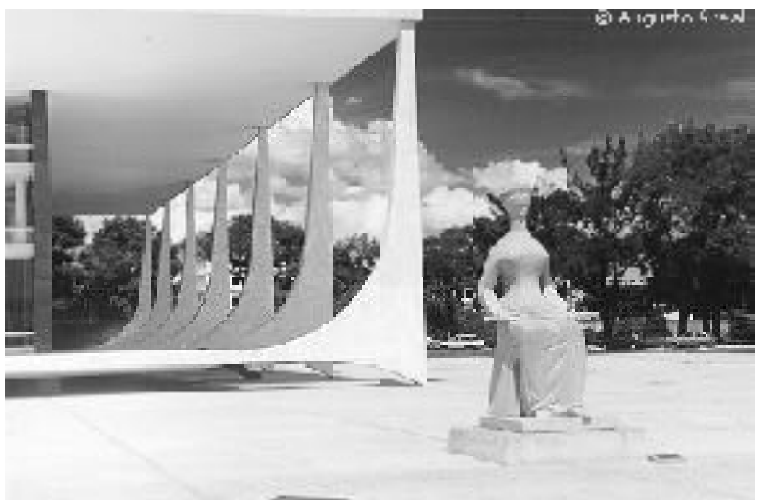

Figura 7 - Escultura "Justiça"

Fonte: http://www.geocities.com/TheTropics/ 3416/tabfotos.htm

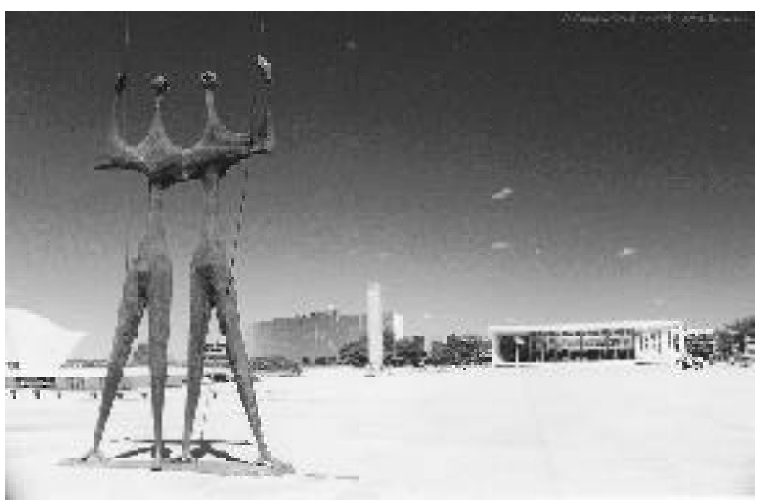

Figura 8 - Os "Guerreiros"

Fonte: http://www.geocities.com/TheTropics/ 3416/tabfotos.htm do diz:

Como destaca Silva (2004, p. 21) quan-

As paisagens são testemunhos visuais de elementos estéticos e simbólicos construídos historicamente e, quando identificados e apropriados, despertam um renovado interesse no lugar visitado e contribuem para estabelecer uma valorização qualitativa. (SILVA, 2004, p. 21)
De acordo com depoimentos de Oscar Niemeyer, o edifício do Congresso é sua realização arquitetônica predileta. Com sua concepção plástica arrojada, a sede do Poder Legislativo é um conjunto arquitetônico onde se destacam as duas cúpulas representando os plenários da Câmara dos Deputados que corresponde à cúpula maior - cúpula convexa - e do Senado Federal representado pela cúpula menor - cúpula côncava - além do edifício de 28 pavimentos, onde funciona a administração das duas Casas legislativas. Esse conjunto de edificações, além da sua representatividade arquitetônica, é dotado de significados associados às principais decisões e manifestações políticas do Brasil.

Os edifícios do Palácio do Planalto e do Supremo Tribunal Federal completam o arranjo arquitetônico modernista da Praça dos três Poderes, igualmente projetados por Oscar Niemeyer. São exemplos que despertam o interesse da visitação turística, não somente por suas expressões arquitetônicas na paisagem da Praça dos Três poderes, mas também pelo museu anteriormente mencionado.

Do grande terraço suspenso que conforma a Praça dos Três Poderes é possível avistar o Palácio da Alvorada (figura 09), residência oficial do Presidente da República, que está situado numa cota mais baixa do sitio de implantação do Plano Piloto, conformado pelo Lago Paranoá. A área de entorno do Palácio é caracterizada pela topografia plana e por uma cobertura vegetal remanescente do cerrado brasileiro. Esses condicionantes da paisagem natural foram intencionalmente preservados no projeto paisagístico de Burle Marx, com o objetivo de valorizar o bioma e as características ambientais do Planalto Central do Brasil.

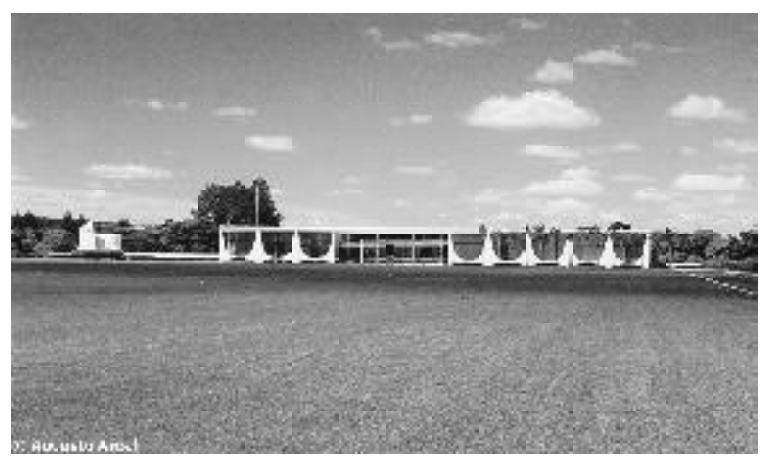

Figura 9 - Palácio da Alvorada

Fonte: http://www.geocities.com/TheTropics/ 3416/tabfotos.htm 
A arquitetura do Palácio da Alvorada é uma das obras-primas de Oscar Niemeyer e foi projetado em 1956, antes mesmo do concurso que escolheu o plano urbanístico da nova capital. Trata-se de um edifício retangular de dois andares e um subsolo, tendo como elemento arquitetônico marcante as colunas que emolduram as fachadas longitudinais, as quais se tornaram símbolo da capital federal. Uma pequena capela lateral completa o conjunto. No hall de entrada se destaca a parede de azulejos dourados de Athos Bulcão, assim como a porta e o vitral da capela. Os jardins do Palácio foram projetados por Burle Marx para compor o conjunto edificado e o sítio de entorno.

A localização privilegiada e a arquitetura do Palácio da Alvorada no contexto da paisagem de Brasília são fatores de atratividade e despertam o interesse turístico. Nesse sentido, pode-se afirmar que a Praça dos Três Poderes funciona também, e principalmente para o turista, como um mirante que possibilita apreciar esta paisagem.

A partir da Praça dos Três Poderes, no sentido oposto à visão do Palácio da Alvorada, se descortina a Esplanada dos Ministérios. No primeiro plano, uma edificação de destaque na paisagem é o Palácio do Itamaraty, sede do Ministério das Relações Exteriores do Brasil. É uma das obras mais conhecidas de Niemeyer, possui a fachada em arcos e painéis decorativos de vários artistas, como Athos Bulcão, Rubem Valentim, Sérgio Camargo, Maria Martins, além de um afresco de Alfredo Volpi e, por fim, é rodeado por um espelho d'água que serve de cenário para a famosa escultura O Meteoro, de Bruno Giorgi (figura 10). Neste exemplo, mais uma vez a categoria de conteúdo pelo detalhamento de suas características é relevante, já que situam as obras no tempo e as individualizam, assim como a valorização do espaço interno e externo através da arquitetura paisagística de Burle Marx.

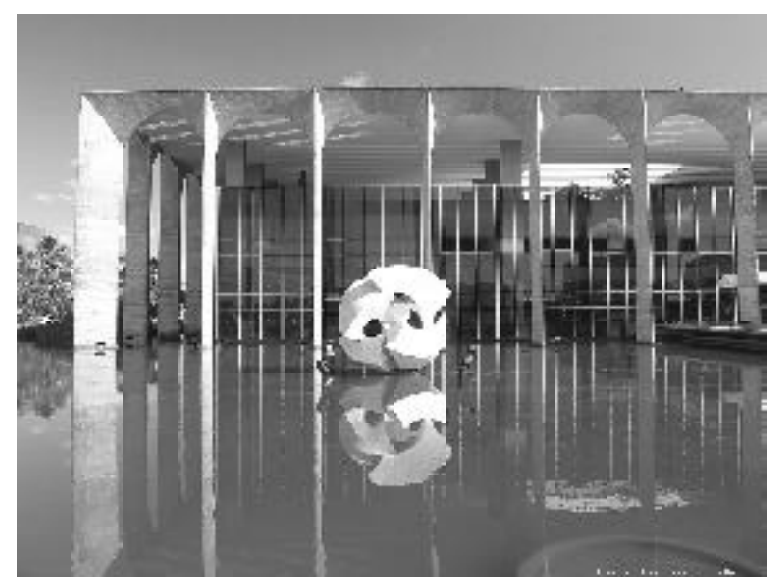

Figura 10 - Palácio do Itamaraty e o "Meteoro". Fonte: http://www.geocities.com/TheTropics/ 3416/tabfotos.htm

Ainda na Esplanada dos Ministérios encontram-se 17 edifícios de construção uniforme que abrigam os Ministérios do Poder Executivo. Nessa perspectiva, esse conjunto de edificações se volta para o que Bullón (2002), chama de centro gravitacional, já que ao final da Esplanada é possível avistar o Congresso Nacional. Assim, esse conjunto arquitetônico uniforme parece estar margeando e condicionando o olhar a uma única direção: o edifício do Congresso Nacional.

Essa perspectiva é acentuada pelas duas fileiras de edifícios idênticos e pela uma vasta área gramada como um tapete verde a ser seguido. Embora se verifique certa monotonia pela uniformidade do conjunto, a sensação transmitida ao observador condiz com o que Cullen (1971) classifica de perspectiva grandiosa, já que a ligação do primeiro plano - a Esplanada - induz a uma sensação de onipresença da paisagem com o foco no edifício do Congresso Nacional.

Na paisagem da Esplanada dos Ministérios se destaca por seu conteúdo e forma o conjunto monumental da Catedral Metropolitana Nossa Senhora Aparecida (figura 11). Trata-se de um exemplo complexo de categorização da paisagem, na medida em que ela assume um papel importante na estética da paisagem da Esplanada dos Ministérios e, particularmente, em sua geometria, interrompendo a uniformidade e, portanto, a monotonia peculiar dessa área da cidade. Além de toda a representação simbólica e da apropriação de significados a ela atribuída. 


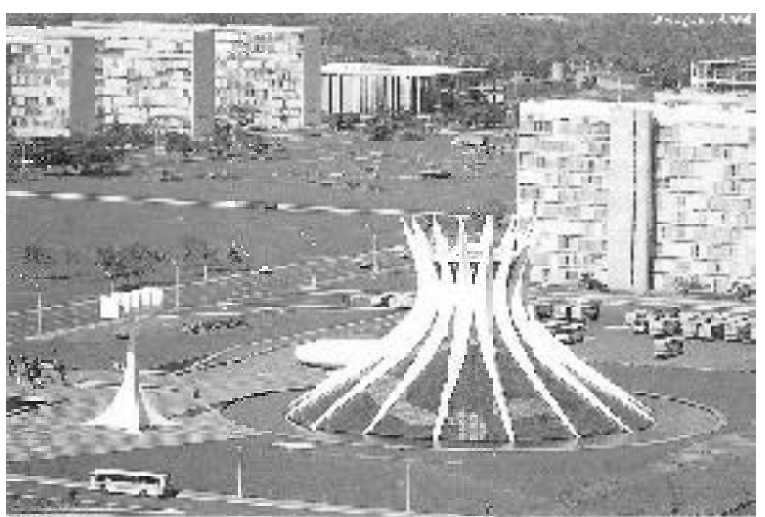

Figura 11-Esplanada dos Ministériose Catedral. Fonte: http://www.geocities.com/TheTropics/ 3416/tabfotos.htm

A catedral de Brasília é um exemplar da arquitetura grandiosa de Oscar Niemeyer. Neste projeto o autor faz uma releitura da disposição do conjunto arquitetônico de Miguel Ângelo para a Catedral de Florença na Itália - nave, batistério e campanário - mas mantém a sua própria expressão arquitetônica, além de dotar à nave de uma planta circular em desnível e de uma cúpula que emerge do plano do terreno e se abre em direção ao firmamento. Esta cúpula é composta por 16 pilares curvos de concreto unidos pelos painéis de vitrais que dão leveza ao conjunto e possibilita a entrada da luz natural ao interior do templo (figura 12).

Além disso, a catedral de Brasília possui um expressivo acervo de obras de arte: no lado externo, as esculturas dos quatro evangelistas, de Alfredo Ceschiatti, os vitrais de Marianne Peretti, as pinturas de Di Cavalcante e um painel no batistério em cerâmica de Athos Bulcão.

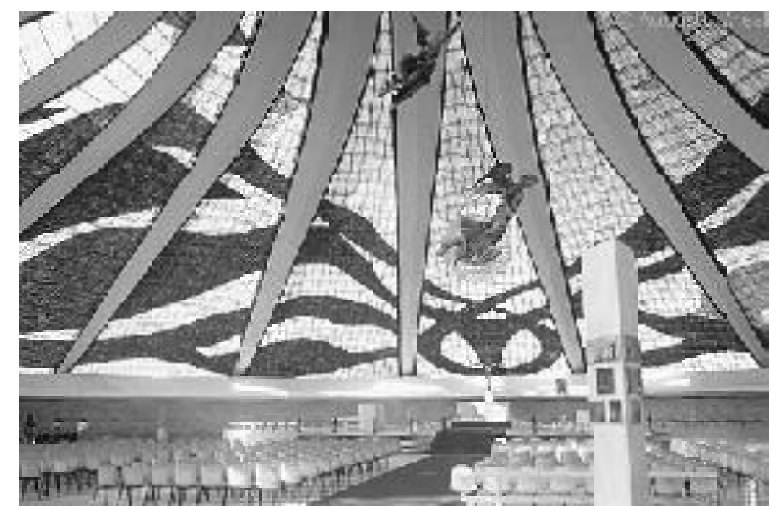

Figura 12 - Interior da Catedral

Fonte: http://www.geocities.com/TheTropics/ 3416/tabfotos.htm
A seqüência do Eixo Monumental para o lado oeste é marcada pela centralidade atribuída à Estação Rodoviária, que corresponde ao centro geográfico do Plano Piloto de Brasília. Neste ponto se verifica o cruzamento do Eixo Monumental com o Eixo Rodoviário.

O autor do projeto da Estação Rodoviária foi Lucio Costa, que concebeu um conjunto de plataformas em quatro níveis. A estação rodoviária é o local onde se pode observar uma maior urbanidade de Brasília, devido à circulação intensa de pessoas e, portanto, imprimindo uma possível primeira impressão da vida urbana. Nesse sentido, Carpintero (1998, p. 154) pontua que "a monumentalidade proposta no projeto de Lúcio Costa é discreta e não ostentatória" e que a cidade foi pensada para o uso da classe média, os funcionários do governo, e que os trabalhadores mais modestos não foram considerados no projeto.

Mas, na prática, no que se refere à urbanidade, verifica-se que nessa área central a cidade se mostrou diferente do imaginado. Segundo Carpintero, Lúcio Costa reconhece isso numa entrevista dado in loco na Rodoviária de Brasília:

[...] Isso tudo é muito diferente do que eu tinha imaginado para esse centro urbano, como uma coisa requintada, meio cosmopolita. Mas não é. Quem tomou conta dele foram os brasileiros verdadeiros que construíram a cidade e estão aí legitimamente. É o Brasil... E eu fiquei orgulhoso disso, fiquei satisfeito. É isto, eu é que estava errado. Eles tomaram conta daquilo que não foi concebido para eles. Então eu vi que Brasília tem raízes brasileiras reais, não é uma flor de estufa como poderia ser. Brasília está funcionando e vai funcionar cada vez mais. $\mathrm{Na}$ verdade o sonho foi menor que a realidade. A realidade foi maior e mais bela. Eu fiquei satisfeito me senti orgulhoso de ter contribuído. (COSTA\& COST, 311, apud CARPINTERO, 1998, p. 154)

Assim, esta área é caracterizada como um ponto nodal, ou ainda como um limite no contexto da paisagem urbana, segundo a classificação de Lynch (1997) e como tal ela estabelece claramente uma mudança na visualidade e na percepção do usuário ou do observador. Esta mudança de cenário para o lado oeste do Eixo Monumental é reforçada pela Torre de Televisão (figura 13), 
projetada também por Lucio Costa, funcionando também como mirante. É o ponto mais alto de todo o Plano Piloto, com $1.224 \mathrm{~m}$, onde é possível ter uma visão completa do Plano Piloto. A torre é uma referencia de Lucio Costa à Torre Eiffel de Paris. Para o turismo a torre é um local bastante visitado e um marco referencial da paisagem urbana, pois ela associa o valor da atratividade proporcionada por seu mirante de observação da cidade, um museu e a feira de artesanatos.

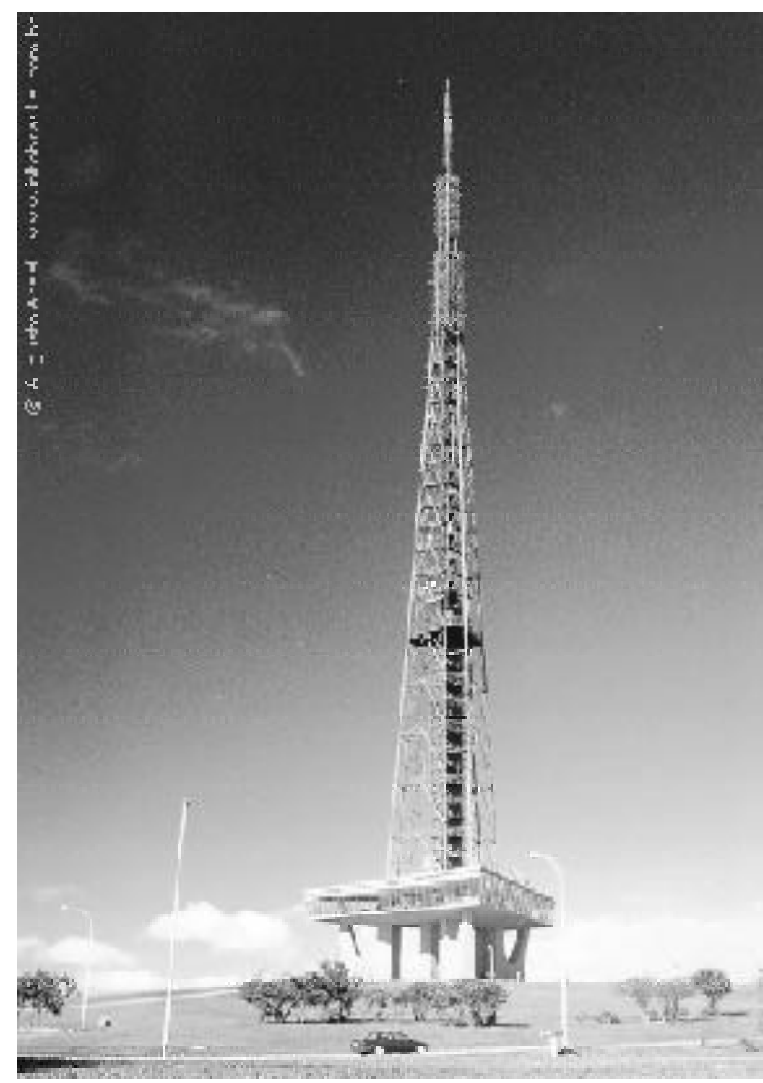

Figura 13 - Torre de TV

Fonte: http://www.geocities.com/TheTropics/ 3416/tabfotos.htm

Outra edificação de relevância no Eixo Monumental oeste é o Palácio do Buriti, projetado pelo arquiteto Nauro Jorge Esteves, que abriga a sede do Governo do Distrito Federal. Seu nome se deve a uma palmeira típica do cerrado brasileiro, denominada buriti. Segundo consta, o plantio da palmeira foi uma sugestão de Israel Pinheiro, construtor e primeiro prefeito da nova capital, em 1959. Posteriormente, essa vegetação que dá o nome ao referido palácio foi tombada pelo Patrimônio Histórico do Distrito Federal.

De acordo com Cullen (1971), as árvores estão entre os mais tradicionais elemen- tos naturais que compõem a paisagem urbana, fazendo referência a elas como "uma presença viva do espaço edificado" (CULLEN, 1971, p. 84).

O Memorial JK (figura 14) é outra edificação que se destaca na paisagem. Projetado por Oscar Niemeyer, originalmente se destinava ao mausoléu de Juscelino Kubitschek. Em exposição permanente dos objetos e fotos do fundador de Brasília esse espaço se caracteriza ademais como um museu, atraindo turistas por seu significado e representatividade histórica.

Então, chegamos à Praça do Cruzeiro, "o marco zero" que além de ser a cota mais elevada do Plano Piloto, 1172m, simboliza o lugar escolhido para a abertura do Eixo Monumental.

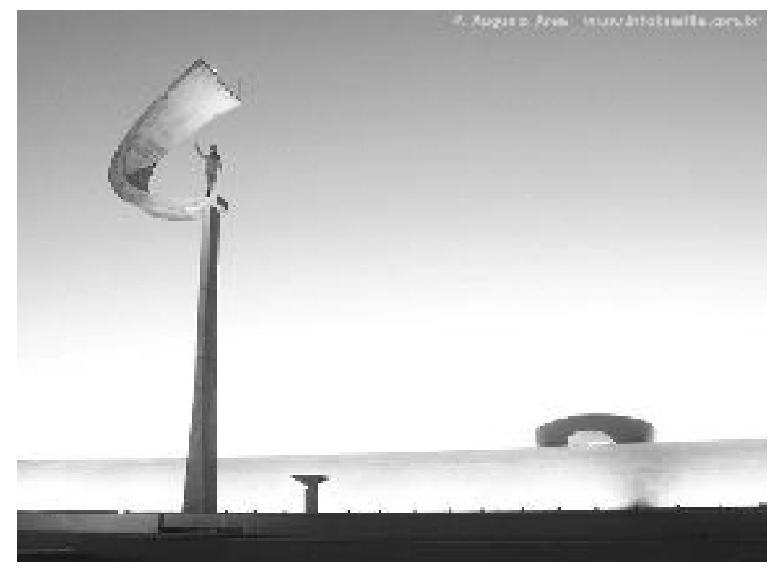

Figura 14 - Memorial JK

Fonte: http://www.geocities.com/TheTropics/ 3416/tabfotos.htm

Atualmente, essa cruz é uma replica da original, a qual foi transferida, por razões de conservação para a Catedral Metropolitana. Segundo Carpintero (1998, p. 119), Lúcio Costa escolheu o triângulo contido entre os braços do lago Paranoá o local para a implantação da cidade e seguindo a linha geométrica de maior declividade, por causa do promotório visível de toda a encosta leste, que confere ao local uma serena monumentalidade, realçada pela água. Assim, Lúcio Costa tirou partido desse condicionamento geográfico para o seu plano piloto. Nesse ponto, seguindo a linha do espigão foi estabelecido o Eixo Monumental e ao longo das curvas de nível lançou o Eixo Rodoviário. Dessa forma, Lúcio Costa expressou o início do seu plano para a cidade: "Nasceu do gesto primário de quem assinala um lugar ou 
dele toma posse: dois eixos cruzando-se em ângulo reto, ou seja, o próprio sinal da cruz" (COSTA, apud CARPINTERO 1998, p. 121).

\section{Considerações finais}

Brasília é uma cidade de onde se originam as principais decisões que conduzem a vida do país, afinal a cidade foi construída com essa finalidade. Nesse cenário, uma junção do sentimento que a cidade desperta e a forma concreta da sua representatividade tornam-se a principal fonte de informação sobre a sua paisagem urbana. Dessa maneira, é possível entender a complexidade de sua formação, na medida em que a forma possui informações, que são aceitas e interpretadas de inúmeras maneiras por cada individuo que se dispõe a conhecê-la. Assim, na medida em que um lugar e a consciência que ele toma de si mesmo, volta-se para a sua afirmação cultural, articulada às afirmações políticas e econômicas, é possível constatar alguns padrões que o personaliza.

Consideramos que as paisagens edificadas, dos menores aos maiores ambientes, são carregadas de informações e de significados, mesmo que incompletos, fazendo com que o cotidiano seja mais representativo e, portanto, mais fácil de entender uma determinada realidade. Mas, de qualquer forma é essa paisagem com seus atributos ambientais e com sua dinâmica sociocultural que atrai a motivação turística. Um cenário repleto de formas, relações, conflitos, revelações e fatos.

A análise efetuada sobre a paisagem de uma área considerada o centro gravitacional de Brasília - o Eixo Monumental - destacando sua potencialidade para o desenvolvimento da atividade turística procura, sobretudo, contribuir com a discussão sobre a importância das paisagens urbanas enquanto atrativo turístico, freqüentemente de grande magnitude, notadamente nas localidades em que os atrativos da paisagem natural não exercem uma forte atração.

Nesse sentido, são numerosos os exemplos de cidades, onde a atividade turística é expressiva e está consolidada, que têm nas suas paisagens urbanas o principal recurso de atratividade turística. Enfim, essa discussão também não pretende ser exaustiva e sim uma abordagem inicial, própria dos estudos exploratórios, que pode ser retomada ou ampliada para outras paisagens urbanas e suas interações com o turismo.

\section{Referências}

BARROS, Nilson Cortez Crocia de. Manual de Geografia do turismo. Pernambuco, Ed. UFPE, 2001.

CARLOS, Ana Fani Alessandri. A Cidade. São Paulo: Contexto, 1999.

CARPINTERO, Antonio Carlos Cabral. Brasília: prática e teoria urbanística no Brasil, 1956-1998. Tese (Doutorado) - USP, 1998.

CASTRO, Iná Elias de. Paisagem e Turismo. De estética, nostalgia e política. In: YÁZIGI, Eduardo (org.). Turismo e paisagem. São Paulo: Contexto, 2002.

COSTA, Lúcio. Relatório do Plano Piloto de Brasilia - Brasília, cidade que inventei. ArPDF, CODEPLAN, DePHA. Brasília, 1991.

CULLEN, Gordon. Paisagem urbana. Lisboa: Edições 70, 1971.

DE OLIVEIRA, Josildete Pereira; FERNANDES, Diogo Luders; STACH, Claudia. A paisagem urbana como recurso turístico: um estudo de caso da paisagem edificada de Irati-PR enquanto atrativo turístico. Turismo - Visão e Ação. UNIVALI. v. 9, n. 1, p. 83-94, Jan./ Abr. 2007.

DE OLIVEIRA, Josildete Pereira. Glossário de Turismo e Hotelaria. Turismo Visão $\mathcal{E}$ Ação. Univali. Edição Especial, 1999.

JUNQUIRA, Luiz Daniel Muniz. Lago Paranoá de Brasília$D F$. Análise dos usos e ocupações do espaço da orla para o lazer. Dissertação (Mestrado) - Universidade do Vale do Itajaí. 2006.

LYNCH, Kevin. A Imagem da Cidade. São Paulo: Martins Fontes, 1997.

RODRIGUES, Adyr Balastreri. Turismo e espaço: rumo a um conhecimento transdisciplinar. São Paulo: Hucitec, 1997.

SANTOS, Milton. O espaço do cidadão. 4. ed. São Paulo: Nobel, 1998.

1982.

Pensando o espaço do homem. São Paulo: Hucitec,

SILVA, Maria da Glória Lanci da. Cidades Turísticas: identidades e cenários de lazer. São Paulo: Aleph, 2004.

VESENTINI, Jose William. A capital da Geopolítica. São Paulo: Ática, 1986.

YÁZIGI, Eduardo. A importância da paisagem. In: YÁZIGI, Eduardo (org.). Turismo e Paisagem. São Paulo: Contexto, 2002

Civilização Urbana: planejamento e turismo. São Paulo: Contexto, 2003.

\section{Sites:}

$<$ http://www.superbrasilia.com/>. Acesso em: 10 maio 2008.

<http://www.geocities.com/TheTropics/3416/ tabfotos.htm>. Acesso em: 10 maio 2008. 